\title{
The effects of internet-delivered intervention for promoting physical activity
}

\author{
Hiroaki Uechi and Nobusuke Tan \\ (Yamaguchi University)
}

\begin{abstract}
This study examined the effectiveness of internet-delivered interventions-comprising recording of daily steps, a daily steps graph, goal setting, integration with a social networking service, personalized reminders urging physical activity, team and individual ranking, and a questionnaire - for promoting physical activity. Participants in the intervention group were 253 workers in five industrial sectors: manufacturing (94); transportation and postal activities (32); education and learning support (38); medical, healthcare, and welfare (63); and services not classified elsewhere (NCE) (26). Analysis of variance was used to test for significant differences in daily step count and exercise self-efficacy according to industrial sector (5 aforementioned groups and a control group) and time (pre/post-intervention). Although the NCE services group had a significantly higher daily step count post-intervention, self-efficacy was not significantly changed in any group. The NCE services group was assumed to use a computer as part of their daily work. This possibly indicates that for the effective use of this intervention, which relies on information and communications technology (ICT), participants must possess media literacy and work in a substantially ICT-focused environment. This study suggests it is necessary to enrich the contents of internet-delivered interventions and simultaneously enhance participants' ability to use personal computers in order to successfully promote physical activity.
\end{abstract}

Key words: e-health, web, health education

According to the National Health and Nutrition Survey conducted in 2012 in Japan (Ministry of Health, Labour and Welfare, 2014), 36.2\% of men and $28.2 \%$ of women engaged in regular exercise (one-time exercise lasting at least 30 minutes, twice a week or more, for more than one year). Although the rate of regular exercise has increased by about 5 points in both men and women over the past 10 years, considering the health benefits of regular exercise, it is still not enough and the rate needs to be increased further. Efforts to promote physical activity include nationally conducted programs such as "Kenko Nippon 21" (Ministry of Health, Labour and Welfare, 2000) as well as many exercise classes and health guidance provided to residents at local government level.

The high costs of targeting large numbers of people for exercise classes and health guidance require appropriate methods of message delivery. For message delivery to a large population, home-based programs are more effective than face-to-face ones. With home-based programs, health providers need not reserve space to hold an exercise class, and participants save on the costs of attending a class.

Recently, home-based programs for health promotion have relied on telephone and booklets, and increasingly personal computers (PCs) due to the rapid development and dissemination of information and communications technology (ICT). In an early review of ICT-based intervention studies published from 2000 to 2006 that aimed to improve physical activity, eating behavior, and weight control, Norman, Zabinski, Adams, Rosenberg, Yaroch, \& Atienza (2007) identified 49 studies (13 on physical activity, 16 on eating behavior, and 20 on weight loss) that met criteria for sample size and study design. Their review focused on studies promoting physical activity, and revealed that many programs were based on the transtheoretical model (TTM; Prochaska, DiClemente, \& Norcross, 1992) or social cognitive theory (Bandura, 1986) and were conducted for about 1-2 


\section{H. Uechi and N. Tan: Internet-intervention}

months. Among 13 of the studies reviewed, only three reported a better outcome for an intervention group than a control group; the other studies indicated either unknown or negative effects.

In a later review of studies published from January 2006 to November 2010, LaPlante \& Peng (2011) analyzed ICT-based intervention studies for promoting physical activity using the web, PC, email, personal digital assistants, mobile phones, and digital games. They found significant intervention effects in four out of seven highquality ICT-based intervention studies, and concluded that definite intervention effects using ICT to promote physical activity remained unknown.

Regarding the lack of a clear effect among ICT-based interventions, Norman et al. (2007) pointed out that program utilization was a problem. In other words, the main reason for the unclear intervention effects was that a large number of participants did not have access to the program's website (i.e., they did not use the program components). Program utilization was influenced by various factors such as the attractiveness of web components, participants' media literacy, and the PC environment, all of which contributed to reducing participants' website access. However, access might be improved by user interface modifications (adopting a touch panel system), by using smartphones and tablets, and by social facilitation (participant competition and cooperation). Gasser, Brodbeck, Degen, Luthiger, Wyss, \& Reichlin (2006) investigated such a smartphone-based intervention for promoting health behavior, compared the intervention effects in single players (individual participation) and team players (group participation), who had social facilitation factors for enhancing participant motivation, and found significant positive effects in both groups.

Furthermore, participants' media literacy and ICT environment may be strongly associated with adaption to an internet-delivered intervention. These media-related factors are influenced by participants' occupational and industrial sector. Therefore it is necessary to consider industrial sectors individually to examine the sector-specific effects of internet-delivered interventions.

In this study, we implemented an internet-based program that satisfied the abovementioned functions and evaluated the program's effectiveness for promoting physical activity.

\section{Methods}

Participants. Participants were recruited from companies located in Shimonoseki City, Japan, via invitational leaflets distributed by Shimonoseki City Hall. Team recruitment was voluntary (one team consisted of a five or fewer members) and required each member's consent. Eligible participants included 311 Japanese adults divided into 76 teams (216 men, mean age $46.3 \pm 12.4$ years; 95 women, $40.8 \pm 10.8$ ). Companies were categorized into 12 industrial sectors based on the Japan Standard Industrial Classification (Ministry of Economy, Trade and Industry, 2014). In this study, which examined intervention effects by industrial sector, industries that consisted of four or fewer teams or less were excluded to preserve the representativeness of the sample. As a result, the intervention groups comprised 253 participants representing five industrial sectors: (1) manufacturing $(n=94 ; 22$ teams; 78 men, mean age $45.6 \pm 12.4$ years; 16 women, $42.5 \pm 9.0$ ); (2) transportation and postal activities ( $n=32 ; 8$ teams; 25 men, $47.0 \pm 11.8$; 7 women, $34.7 \pm 10.9)$; (3) education and learning support $(n=38$; 9 teams; 19 men, $48.9 \pm 11.4 ; 19$ women, $36.8 \pm 10.2)$; (4) medical, healthcare, and welfare ( $n=63 ; 17$ teams; 29 men, $46.3 \pm 11.7 ; 34$ women, 45.6 \pm 10.0 ); and (5) services not classified elsewhere (NCE) $(n=26 ; 6$ teams; 18 men, $59.7 \pm 10.0 ; 8$

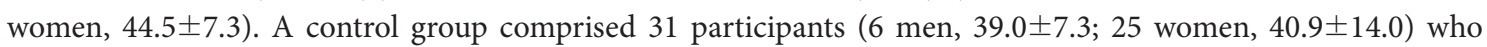
worked at Shimonoseki City Hall. Participants were instructed to work as usual during the intervention period.

Program duration. The program was conducted for 40 days from early October 2013 to mid-November 2013. The program was divided into six weeks of seven days each, counting from the program start date. Only the sixth week consisted of five days that included Saturday and Sunday.

Program components. In the intervention group, daily physical activity was conducted using the "Active Lifestyle Campaign," an internet-based program developed by the physical education and sports psychology laboratory at Yamaguchi University, based on the theoretical framework of social cognitive theory (Bandura, 1986) and the TTM (Prochaska, Dieclemente, \& Norcross, 1992). The program's interface was suitable for a touch panel and could also be operated easily from a smartphone or tablet. The program included a variety of functions, 


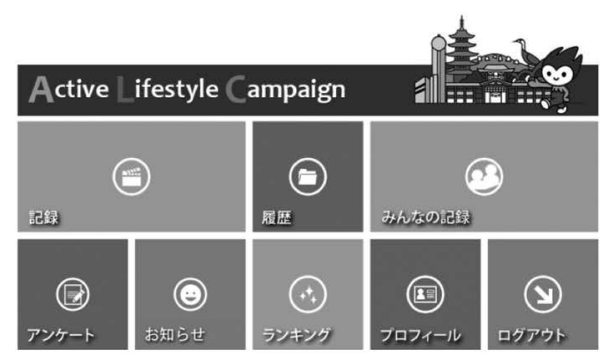

Top page

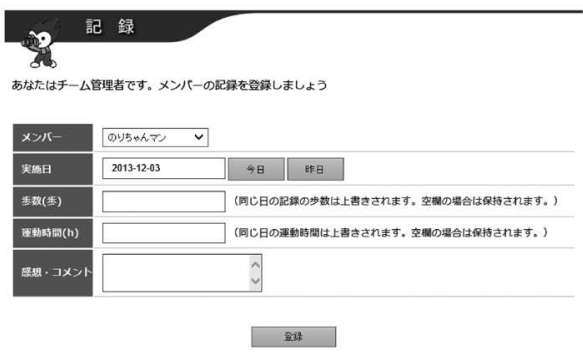

\section{Recording daily steps page}

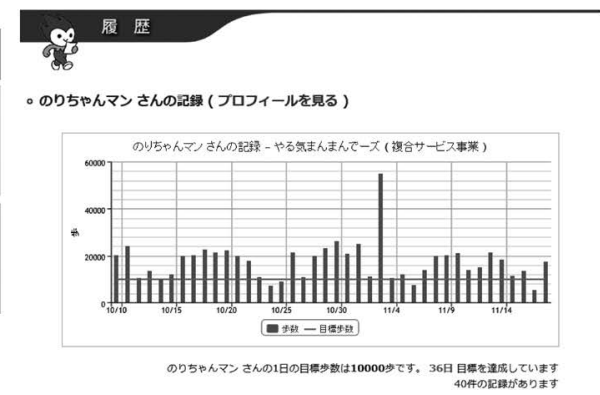

Graph of daily steps page

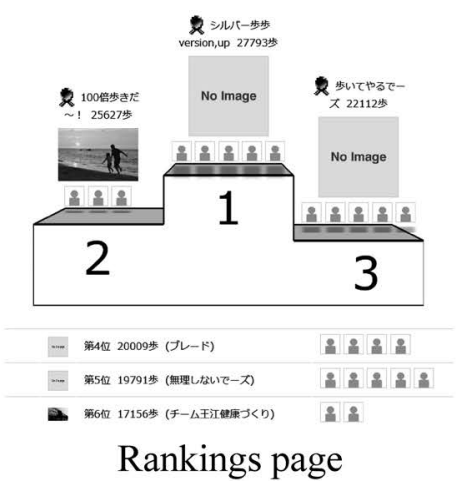

Figure 1. Sample web pages from the Active Lifestyle Campaign

such as (1) recording of daily steps, (2) a daily steps graph, (3) goal setting, (4) integration with a social networking service (SNS), (5) personalized reminders urging physical activity, (6) team and individual rankings, and (7) a questionnaire on exercise self-efficacy (see Figure 1). Details of each function are as follows.

(1) Recording of daily steps: Participants used their own pedometer to measure their daily steps. Each day, daily steps were recorded on their own web page, and any unrecorded daily steps could be recorded retrospectively.

(2) Daily steps graph: A bar graph was created automatically from logged daily steps records. With the bar graph, participants could visualize changes in their number of steps during the program.

(3) Goal setting: Participants could set a goal number of daily steps, depicted as a red line on the bar graph. The bar graph also displayed the number of times that the goal was achieved during the program.

(4) Integration with an SNS: A diary could be maintained at the same time as the daily steps were recorded. This diary was viewable and other participants could comment on them.

(5) Tailored messages: Participants received personalized reminders urging physical activity that accorded with their questionnaire responses (see below). Each tailored message remained on the web page for one week. Contents of tailored messages were constructed on self-efficacy, decision-making, and process of change based on the TTM (Takenaka \& Togashi, 2005). In addition, program providers continuously delivered to each participant's web page other useful information such as correct walking style, recommended amount of physical activity, and exercise- and health-related guidance.

(6) Ranking: The top 10 ranking daily steps were presented by individual and by team. Also, the rankings of industrial sectors with fewer than 11 teams were displayed more personally (e.g., "You are ranked $\bigcirc \bigcirc$ " ).

(7) Questionnaire: The questionnaire measured exercise self-efficacy and included a question on the usability of the internet-based program.

Program evaluation measurements. In the intervention group, daily steps were measured as outcome 


\section{H. Uechi and N. Tan: Internet-intervention}

indicators for the program evaluation. Also, the process of this program was evaluated in terms of exercise selfefficacy, usability of the internet-based program, program utilization, and changes in ranking. For the control group, indicators were both daily steps and exercise self-efficacy. Exercise self-efficacy was measured using the Exercise Self-Efficacy Scale (Oka, 2003). This scale is composed of four items (e.g., "Even when I am a little tired, I am confident I will exercise;" "Even when I am not in the mood to exercise, I am confident I will exercise" ) scored on a 5-point Likert scale ranging from 1 (not confident) to 5 (confident). Usability of the internet-based program was measured by asking a single question "How did you feel about recording daily steps using a PC or other device?" with five response options ranging from "not hard at all" to "very hard." Program utilization was measured by the number of participants logging in to the program's website during the intervention. Finally, weekly changes in rank-order of the top 10 teams and individuals were reviewed.

Procedures. Five accounts (IDs) were distributed to each team: one for the leader and four for intervention group members. These IDs were needed to log onto the program's website. The leader's ID permitted the leader to record the daily steps of any team member not familiar with a PC. In addition, for both the intervention and control groups, exercise self-efficacy was asked during the first and last weeks. The intervention group also answered a question about the usability of the program during the last week.

Statistical analysis. For the program's outcome evaluation, two-way analysis of variance (ANOVA) was used to examine differences in average daily steps per week by industrial sector (manufacturing; transportation and postal activities; education and /learning support; medical, healthcare, and welfare; NCE service industry; and control group) and time (first week and last week). For the process evaluation, a two-way ANOVA was used to analyze differences in the exercise self-efficacy score by industrial sector (the five industrial groups noted above and the control group) and time (first week and last week). Significance was set at 0.05 . All statistical analyses were conducted using SPSS Statistics version 11.0 (IBM, Japan).

\section{Results}

Daily steps. ANOVA results for daily steps per week revealed a main effect of industrial sector $(F(5 / 250)=$ 5.33, $p<.001$ ) and an interaction between industrial sector and time $(F(5 / 250)=3.21, p<.01)$ (Table 1$)$. Furthermore, results of the simple main effect test showed a significant difference between daily steps on the first and last week only in the NCE service industry group.

Exercise self-efficacy. ANOVA results for the exercise self-efficacy score revealed a main effect of industrial sector $(F(3 / 153)=3.79, p<.01)$ (Table 1$)$. The control group's score was significantly lower than those of the manufacturing, transportation and postal activities, and NCE service industry groups.

Usability of the internet-based program. Table 2 presents the results of the usability of the internet-based program. Overall, about $60 \%$ of participants answered "not hard" or "not hard at all." Results of a $\chi^{2}$ test and residual analysis showed a significantly higher rate of "not hard" responses in the NCE service industry group (adjusted residuals: 2.4) and "hard" responses in the medical, healthcare, and welfare group (adjusted residuals: 6.4) than in the other groups.

Program utilization. The NCE group had the largest number of participants logging in at least once each week, and the medical, healthcare, and welfare group had the fewest (Table 3).

Daily steps rankings. At the end of the program, we reviewed all changes in rank order of the top 10 teams and individuals that occurred during the program. We found no drastic changes in rank order during the program for either teams or individuals (data not shown).

\section{Discussion}

The main result in our study was that the NCE service industry group had significantly increased its daily steps by the end of the program. This group consisted of a temporary employment agency and a commerce and industry society. We assumed the group's workers were familiar with PCs and used them daily in their work. In 
Table 1 Mean and standard deviation (SD) of daily steps and exercise self-efficacy scores

\begin{tabular}{|c|c|c|c|c|c|c|}
\hline & $n$ & $\begin{array}{c}\text { Pre-program } \\
\text { (1 week) }\end{array}$ & $\begin{array}{l}\text { Post-program } \\
\text { (6 weeks) }\end{array}$ & $\begin{array}{c}\text { Industrial sector } \\
F\end{array}$ & $\begin{array}{c}\text { Time } \\
F\end{array}$ & $\begin{array}{c}\text { Interaction } \\
F\end{array}$ \\
\hline Daily steps & & & & \multirow{7}{*}{$\begin{array}{c}5.33^{* * *} \\
\text { NCE services }>\text { Control, } \\
\text { Manufacturing; NCE } \\
\text { services }>\text { Medical, } \\
\text { healthcare, and welfare }\end{array}$} & \multirow[t]{7}{*}{2.89} & \multirow[t]{7}{*}{$3.21^{* *}$} \\
\hline Manufacturing & 92 & $\begin{array}{l}11517.2 \\
(5649.1)\end{array}$ & $\begin{array}{l}10893.5 \\
(5321.6)\end{array}$ & & & \\
\hline Transportation and postal activities & 29 & $\begin{array}{c}8630.0 \\
(2720.1)\end{array}$ & $\begin{array}{c}9135.0 \\
(3042.1)\end{array}$ & & & \\
\hline Education and learning support & 30 & $\begin{array}{c}8935.1 \\
(2909.0)\end{array}$ & $\begin{array}{c}8966.5 \\
(3871.1)\end{array}$ & & & \\
\hline Medical, healthcare, and welfare & 54 & $\begin{array}{c}8459.5 \\
(3391.9)\end{array}$ & $\begin{array}{c}8438.2 \\
(4281.1)\end{array}$ & & & \\
\hline NCE services & 25 & $\begin{array}{l}10970.0 \\
(6441.3)\end{array}$ & $\begin{array}{l}13268.7 \\
(7842.7)\end{array}$ & & & \\
\hline Control & 26 & $\begin{array}{c}8235.9 \\
(2031.1)\end{array}$ & $\begin{array}{c}8397.2 \\
(3171.7)\end{array}$ & & & \\
\hline Exercise self-efficacy & & & & $3.79^{* *}$ & 2.42 & 1.65 \\
\hline Manufacturing & 48 & $\begin{array}{l}12.3 \\
(4.4) \\
\end{array}$ & $\begin{array}{l}12.6 \\
(5.0)\end{array}$ & $\begin{array}{l}\text { Manufacturing; } \\
\text { Transportation and }\end{array}$ & & \\
\hline Transportation and postal activities & 18 & $\begin{array}{l}12.3 \\
(3.5)\end{array}$ & $\begin{array}{l}12.2 \\
(3.9)\end{array}$ & NCE services $>$ Control & & \\
\hline Education and learning support & 15 & $\begin{array}{l}11.7 \\
(2.4)\end{array}$ & $\begin{array}{l}12.3 \\
(2.9)\end{array}$ & & & \\
\hline Medical, healthcare, and welfare & 30 & $\begin{array}{l}11.1 \\
(4.6)\end{array}$ & $\begin{array}{l}10.7 \\
(4.2)\end{array}$ & & & \\
\hline NCE services & 22 & $\begin{array}{l}11.2 \\
(4.3)\end{array}$ & $\begin{array}{l}13.3 \\
(4.8)\end{array}$ & & & \\
\hline Control & 26 & $\begin{array}{c}8.7 \\
(3.3)\end{array}$ & $\begin{array}{c}8.8 \\
(2.9)\end{array}$ & & & \\
\hline
\end{tabular}

Note. $\mathrm{NCE}=$ Not classified elsewhere. Values in parentheses are standard deviations. $* * p<.01,{ }^{* * *} p<.001$

other words, internet-based programs depend upon participants' media literacy, and the presence of PCs in the office environment has a large impact on PC utilization. As a result, these factors were able to contribute to increases in physical activity as an outcome measure. Moreover, we can state that program utilization was an important contributing factor to the intervention effect for promoting physical activity. For instance, as the NCE service group logged into the program most often, there was a significant intervention effect. However, to produce this intervention effect, various factors besides program utilization are likely involved. We infer that the type of work in each industrial sector is one of these factors. Compared with other industrial groups, we assumed the NCE service industry group performed not only sedentary work but also outside work such as sales. Therefore, having the opportunity to manage their work to intentionally increase physical activity influences the intervention effect.

Regarding the exercise self-efficacy score, especially in the NCE service industry group, a relatively large, albeit not significant, change occurred between the first and last weeks of the program. Our findings indicate the inefficacy of the messages delivered to participants for increasing exercise self-efficacy related to health and exercise. Therefore, the content of the messages must be refined and improved so that participants will read the messages. For instance, arrival of a new message prompts the display of a notification sign on the participant's 
Table 2 Usability of the internet-based program in the industrial sectors

\begin{tabular}{lcccccc}
\hline & $n$ & $\begin{array}{c}\text { Not hard } \\
\text { at all }\end{array}$ & Not hard & N/A & $\begin{array}{c}\text { Somewhat } \\
\text { hard }\end{array}$ & Very hard \\
\hline $\begin{array}{l}\text { Manufacturing } \\
\text { (adjusted residual) }\end{array}$ & 56 & 18 & 12 & 6 & 12 & 8 \\
& & $(32.1)$ & $(21.4)$ & $(10.7)$ & $(21.4)$ & $(14.3)$ \\
& & 1.5 & -2.7 & -0.4 & 0.7 & 1.6 \\
\hline $\begin{array}{l}\text { Transportation and postal activities } \\
\text { (adjusted residual) }\end{array}$ & 20 & 4 & 9 & 3 & 3 & 1 \\
& & $(20.0)$ & $(45.0)$ & $(15.0)$ & $(15.0)$ & $(5.0)$ \\
\hline $\begin{array}{l}\text { Education and learning support } \\
\text { (adjusted residual) }\end{array}$ & 19 & -0.6 & 1.0 & 0.5 & -0.4 & -0.7 \\
& & $(21.1)$ & $(42.1)$ & $(15.8)$ & $(10.5)$ & $(10.5)$ \\
& & -0.4 & 0.7 & 0.6 & -1.0 & 0.2 \\
\hline $\begin{array}{l}\text { Medical, healthcare, and welfare } \\
\text { (adjusted residual) }\end{array}$ & & 11 & 3 & 6 & 11 & 3 \\
& & $(32.4)$ & $(8.8)$ & $(17.6)$ & $(32.4)$ & $(8.8)$ \\
\hline $\begin{array}{l}\text { NCE services } \\
\text { (adjusted residual) }\end{array}$ & 22 & 1 & -3.1 & 1.2 & 2.4 & -0.1 \\
\hline Total & & $(4.5)$ & $(95.5)$ & $(0.0)$ & $(0.0)$ & $(0.0)$ \\
& & -2.4 & 6.4 & -1.9 & -2.4 & -1.6 \\
\hline
\end{tabular}

Note. NCE $=$ Not classified elsewhere.

Values in parentheses are percentages.

$\chi^{2}(16)=58.80, p<.001$

web page. However, this notification was automatically deleted after about one week even if the message page was never accessed. To ensure that participants read the messages, additional functions are needed to prevent the notification from disappearing or to stop other functions until the participant has accessed the message page.

Regarding the program's usability, more than half of the participants answered that usability was not difficult. However, we observed a bias between industrial groups in that more than $40 \%$ of those in the medical, healthcare, and welfare group answered that usability was "hard" or "very hard." This reflects, in part, that participants in this group (mainly pharmacy and nursing-care facility workers) did not work in an environment with easy access to smartphones and PCs during break time. As Table 2 shows, causality between frequency of program access and program usability does not show a strong relationship.

Concerning the program's ranking function, we expected participants to be motivated by the real-time display of their ranking. However, we did not find any large changes in ranking during the program. The higher ranked individuals and teams remained consistently fixed throughout the program, suggesting that competition by ranking system helps maintain and increase the motivation of high ranked individuals and teams. On the other hand, competition by rank order did not affect low ranking individuals or teams. In future research we need to explore other motivational methods for physically inactive individuals.

We also did not observe a lively exchange of comments between participants via the SNS function. Because many participants were not acquainted with other team members, it is not unreasonable that there would be some resistance to exchanging comments. To promote an exchange of comments between participants, we need to provide common topics such an attractive roads or neighborhood sites for walking.

This study has several limitations. First, because participants used their own pedometers, various types of devices were used in this study. Strictly speaking, to eliminate measurement error, all participants should use the same pedometer, but this was precluded due to budgetary reasons. Therefore, the program evaluation did not compare daily steps between participants, but rather analyzed daily-step increases or decreases within a 
Table 3 Number of participants logging into the program's website during the intervention

\begin{tabular}{|c|c|c|c|c|c|c|c|}
\hline & \multirow{2}{*}{$\begin{array}{c}\text { Total } \\
\text { number }\end{array}$} & \multicolumn{6}{|c|}{ Number of participants logging in at least once each week } \\
\hline & & Week 1 & Week 2 & Week 3 & Week 4 & Week 5 & Week 6 \\
\hline \multirow[t]{2}{*}{ Manufacturing } & 94 & 49 & 64 & 70 & 56 & 69 & 82 \\
\hline & & $(52.1)$ & $(68.1)$ & $(74.5)$ & $(59.6)$ & $(73.4)$ & $(87.2)$ \\
\hline \multirow[t]{2}{*}{ Transportation and postal activities } & 32 & 25 & 25 & 25 & 23 & 27 & 27 \\
\hline & & $(78.1)$ & $(78.1)$ & $(78.1)$ & $(71.9)$ & $(84.4)$ & $(84.4)$ \\
\hline \multirow[t]{2}{*}{ Education and learning support } & 38 & 27 & 29 & 26 & 25 & 25 & 30 \\
\hline & & $(71.1)$ & $(76.3)$ & $(68.4)$ & $(65.8)$ & $(65.8)$ & $(78.9)$ \\
\hline \multirow[t]{2}{*}{ Medical, healthcare, and welfare } & 63 & 31 & 36 & 35 & 31 & 34 & 38 \\
\hline & & $(49.2)$ & $(57.1)$ & $(55.6)$ & $(49.2)$ & $(54.0)$ & $(60.3)$ \\
\hline \multirow[t]{2}{*}{ NCE service } & 26 & 24 & 24 & 23 & 24 & 17 & 24 \\
\hline & & $(92.3)$ & $(92.3)$ & $(88.5)$ & $(92.3)$ & $(65.4)$ & $(92.3)$ \\
\hline \multirow[t]{2}{*}{ Total } & 253 & 156 & 178 & 179 & 159 & 172 & 201 \\
\hline & & $(61.7)$ & $(70.4)$ & $(70.8)$ & $(62.8)$ & $(68.0)$ & $(79.4)$ \\
\hline
\end{tabular}

Note. NCE $=$ Not classified elsewhere.

Values in parentheses are percentages.

participant to minimize any pedometer measurement errors. Retesting using the same pedometer is necessary in future work. Second, this program was conducted in a rural city with a population of 300,000. Many participants commuted by car because of inadequate public transportation. In the case of participants using public transportation, we could have provided more options for physical activity such as getting off the train one stop earlier and walking to the workplace from there. Our results might be different if the research were conducted in a metropolitan area such as Osaka and Tokyo, where the majority of commuters have access to public transportation. Third, though we examined the difference of intervention effects between each industrial sector, it is necessary to consider differences in occupational tasks within each sector (e.g. work that is primarily conducted while sedentary, standing, or walking) in further research. In the future, the number of internet-based programs for health education is expected to grow. We must continue to develop more effective programs by overcoming the abovementioned limitations.

\section{References}

Bandura, A. (1986). Social foundations of thought and action: A social cognitive theory. NJ: Englewood Cliffs.

Gasser, R., Brodbeck, D., Degen, M., Luthiger, J., Wyss, R., \& Reichlin, S. (2006). Persuasiveness of a mobile lifestyle coaching application using social facilitation. Persuasive Technology Lecture Notes in Computer Science, 3962, 27-38.

Laplante, C., \& Peng, W. A. (2011). Systematic review of e-health interventions for physical activity: An analysis of study design, intervention characteristics, and outcomes. Telemed. J. E. Health., 17, 509-523.

Ministry of Economy, Trade and Industry (2014). The Japan Standard Industrial Classification http://www.stat. go.jp/index/seido/sangyo/19-3.htm (February 7, 2014).

Ministry of Health, Labour and Welfare (2000). Kenko Nippon21 http://www.mhlw.go.jp/stf/ shingi/2r98520000008f2q.html\#shingi45 (February 7, 2014).

Ministry of Health, Labour and Welfare (2014). The results of National Health and Nutrition Survey in 2012 http://www.mhlw.go.jp/stf/houdou/0000032074.html. (February 7, 2014).

Norman, G. J., Zabinski, M. F., Adams, M. A., Rosenberg, D. E., Yaroch, A. L., \& Atienza, A. A. (2007). A review of eHealth interventions for physical activity and dietary behavior change. Am. J. Prev. Med., 33, 336-345. 
Oka, K. (2003). Stages of change for exercise behavior and self-efficacy for exercise among middle-aged adults. Nippon Koshu Eisei Zasshi, 50, 208-215 (in Japanese).

Prochaska, J. O., DiClemente, C. C., \& Norcross, J. C. (1992). In search of how people change. Applications to addictive behaviors. American Psychologist, 47, 1102-1114.

Takenaka, K., \& Togashi, Y. (2005). Guidebook of behavioral change for exercise leader. http://takenaka-waseda. jp/lifestyle/book_swf.html (February 7, 2014).

(Received September 1, 2014; Accepted August 13, 2015) 